\title{
Self - Control Tasks Depend on Glucose Levels in Students
}

Ababio GK ${ }^{1 *}$, Adu-Bonsaffoh $\mathrm{K}^{2,3}$, Bosomprah $\mathrm{S}^{4}$, Aryee NA ${ }^{1}$, Khurshid K ${ }^{5}$, Antwi-Boasiako $\mathrm{C}^{3}$, Morvey $\mathrm{D}^{6}$, Dzudzor B ${ }^{1}$ and Chaplin WB $^{5,7}$

${ }^{1}$ University of Ghana School of Biomedical and Allied Health Sciences, Medical Biochemistry, Ghana

${ }^{2}$ Department of Obstetrics and Gynecology, Korle-Bu Teaching Hospital, Ghana

${ }^{3}$ Department of Physiology, University of Ghana School of Biomedical and Allied Health Sciences, Ghana

${ }^{4}$ School of Public Health, Department of Biostatistics, University of Ghana, Legon, Accra, Ghana

${ }^{5}$ Department of Population Psychology, St. John's University, Jamaica

${ }^{6}$ The GEMP program, University of Ghana Medical School, Ghana

${ }^{7}$ School of Medicine, New York state University, USA

\begin{abstract}
Background: Burgeoning evidences have correlated self-control to desirable outcomes. A recent work found in literature has indicated that self-control relied on glucose; but there is no such data in Ghana. Hence, a replicative study is needed to investigate this further and this was the focus of the current study.
\end{abstract}

Aim: The purpose was to determine the association between blood glucose levels and self - control score in medical students under exams condition.

Method: The convenience sample consisted of 105 first year medical students of the University of Ghana Medical School (UGMS). These students' were interviewed using a structured questionnaire for demographic, self -control information and clinical information after ethical clearance and informed consent. Three $\mathrm{mL}$ venous blood samples were obtained for determination of blood sugar levels before mini students' exams and 10 minutes after students' interim assessment. The data obtained was entered into an excel spread sheet (Microsoft company, USA) and analyzed using SPSS version 18

Results: Self-control schedule (SCS) formed a unique pattern with blood glucose levels. However, there was no relationship between gender and SCS [chi-square $(2 \mathrm{df})=0.120, p=0.942$ ]; but with the introduction of interim assessment as the stressor, SCS in females increased with increased exams score.

Conclusion: Self-control task could possibly depend on glucose.

Keywords: Indicators; Fasting plasma glucose; Self-control; Academic performance

\section{Introduction}

Self-control is the ability to override one's automatic responses and controlling emotions, thoughts and behavior in cognizance to societal norms [1]. It facilitates adherence to laws and morals. Burgeoning evidences have correlated good self-control to a wider range of effective coping skills, good academic performance and other desirable outcomes [2-4]. For instance, self-control allows people to suppress prejudices and stereotypes [5-8], and make them respond positively [3] to impress others [9].

The self - control scale, an indicator of learned resourcefulness, in this case assesses the individual's general repertoire of self-control behavior as well as tendencies to use those behaviors when experiencing everyday problems or daily hassles $[10,11]$.

Literature suggests that, self-control when coupled with good diet, in stressful circumstances tend to influence one's coping skills [12,13]. This implied that self-control relied on some form of a limited energy resource [1,14]. An inter-relationship of metabolism has clarified the idea that any food intake (e.g. carbohydrate, proteins, or lipids) could generate this energy in the form of ATP (adenosine triphosphate). Glucose, being the precursor of carbohydrate [15-17] can also be generated from the non-carbohydrate sources (e.g. proteins and lipids); and the brain solely depends on this glucose for functioning $[18,19]$. This therefore, is consistent to laboratory studies that indicated that after subjects completed an initial self-control task, they performed worse on a second self-control task compared to participants whose initial task did not require self-control [20]. In another study, resisting the temptation to eat cookies caused some participants to give up faster on a frustrating task [21]. Therefore, if academic examinations are perceived by unprepared students as frustrating events, then, it would be a good model to investigate the indicators of learned resourcefulness and its associations with academic performance in students; hence the focus.

\section{Materials and Methods}

This longitudinal study involved one-hundred and five (105) level 200 medical students and excluded all those who failed to comply at the Department of Medical Biochemistry of University of Ghana Biomedical and Allied Health Sciences, Korle-Bu, Accra, Ghana. A questionnaire for clinical information such as self-control schedule (SCS) was obtained after informed consent and ethical approval (MS-Et/M.5-P3.4/2013-2014) by the institution. Weights and heights were obtained and computed for body mass index (BMI). At risk for overweight was defined using the international body mass index (BMI) cutoff points by the World Health Organization's (WHO) International Obesity Task Force. Students' knowledge acquisition involved the calculation of BMI and calories of each person per day. Students

*Corresponding author: Ababio GK, University of Ghana School of Biomedical and Allied Health Sciences, Medical Biochemistry, Ghana, Tel: +233 20 8182253; E-mail: graceababio2002@yahoo.com

Received: April 23, 2015; Accepted: June 13, 2015; Published June 15, 2015

Citation: Ababio GK, Adu-Bonsaffoh K, Bosomprah S, Aryee NA, Khurshid K, et al. (2015) Self - Control Tasks Depend on Glucose Levels in Students Biochem Anal Biochem 4: 192. doi:10.4172/2161-1009.1000192

Copyright: (c) 2015 Ababio GK, et al. This is an open-access article distributed under the terms of the Creative Commons Attribution License, which permits unrestricted use, distribution, and reproduction in any medium, provided the original author and source are credited. 
malnutrition status was assessed using the MUST tool (www.bapen.org. uk). Individual caloric intake was calculated using the site (http://www. freedieting.com/tools/calorie_calculator.htm).

Three $\mathrm{mL}$ venous blood samples were taken for the determination of blood sugar levels, total cholesterol and HDL cholesterol levels before exams using the chemistry automated analyser. Coronary risk index was obtained by dividing total cholesterol levels with the corresponding HDL-cholesterol level. Random blood sugar levels (RBS) was also determined ten (10) minutes after students' interim assessment. The data obtained was entered into an excel spread sheet (Microsoft company, USA) and analyzed using SPSS version 18.

\section{Statistical Analysis}

The independent variables were age, calories per day, body mass index, and blood sugar levels. The major dependent variable was selfcontrol task. The self-control scale or schedule (SCS) ranged from "very characteristic of me" $(+3)$ to "very uncharacteristic of me" $(-3)$, and was used to assess the application self - addressed statements to control emotional responses, problem-solving strategies, perceived self-efficacy, and the ability to delay immediate gratification.

As some of the individual response had missing items, it was not appropriate to perform summation, as this would have bias the study since the sum would be too low. A modified summation score was computed by first calculating the mean of the non-missing responses for each person and then multiplying that mean by 36 to get an unbiased sum. Tertiles were then generated for SCS. A student was classified as having low self-control (less than 33rd percentile), moderate selfcontrol (33rd to 66th percentile), or high self-control (above 66th percentile) using the tertiles.

\section{Results}

SCS seemed to form a certain pattern with blood glucose levels (Table 1). There seemed to be no relation between gender and SCS [chisquare $(2 \mathrm{df})=0.120, \mathrm{p}=0.942]$. However, when a stressor (e.g. interim assessment) was introduced, SCS in females increased with increased exams score unlike that found in males. Test between-subjects effects (Table 2) significantly showed that students differed on the SCS variable and this in turn depended on the SCS groupings made by gender (Table 1).

\section{Discussion}

The current study was consistent with literature on the fact that selfcontrol task relied on glucose $[1,12-14,18-23]$. The mild fluctuations seen in self-control schedule with gender by other variables in the current study seem to explain the depletion and replenishment of resources (Tables 1 and 2) defined by the body's allocation upon a particular demand.

Academic examinations seemed to be a natural and a situational stressor that could result in anxiety and also reflect as a disturbed homeostasis of the body. This particular stressor needs careful mobilization of resources. The current study therefore provided a laudable insight on individual differences e.g. the same examination task depleted some people more than others -a prominent reflection on physiological capabilities and response patterns.

A simple survey had also suggested sleep and rest to replenish the ability to exert self-control [24]. It is also eminent that the benefits of sleep and rest [24] are mediated by glucose and could possibly signal that, other prominent factors could be eligible. For example, a person with sufficient glucose, who utilizes it efficiently but had little sleep afterwards, might not be effective at self-control. In this study, a quick

\begin{tabular}{|c|c|c|c|c|c|c|}
\hline \multirow{3}{*}{ Variables } & \multicolumn{6}{|c|}{ Self -control schedule ${ }_{(105)}$} \\
\hline & \multicolumn{3}{|c|}{ Males $_{(56)}$} & \multicolumn{3}{|c|}{ Females $_{(49)}$} \\
\hline & $\operatorname{Low}_{(20)}$ & Moderate $_{(17)}$ & $\mathrm{High}_{(19)}$ & $\operatorname{Low}_{(16)}$ & Moderate $_{(16)}$ & $\mathrm{High}_{(17)}$ \\
\hline Age & $19.80(0.30)^{*}$ & $20.11(0.20)$ & $19.60(0.20)$ & $19.70(0.20)$ & $19.70(0.30)$ & $20.30(0.30)$ \\
\hline Calories per day & $1949.00(179.40)$ & $2050.50(126.90)$ & $2128.20(103.60)$ & $2015.40(117.50)$ & $2177.70(139.00)$ & $2124.80(117.50)$ \\
\hline Risk of malnutrition & $0.30(0.13)$ & $0.41(0.14)$ & $0.42(0.13)$ & $0.19(0.14)$ & $0.31(0.14)$ & $0.41(0.14)$ \\
\hline FBS baseline & $5.30(0.22)$ & $5.14(0.17)$ & $5.21(0.16)$ & $5.36(0.16)$ & $5.44(0.19)$ & $5.17(0.19)$ \\
\hline FBS before exams & $4.30(0.24)$ & $4.24(0.20)$ & $4.40(0.19)$ & $4.76(0.21)$ & $4.64(0.20)$ & $4.80(0.30)$ \\
\hline RBS after exams & $6.25(0.48)$ & $5.88(0.43)$ & $6.10(0.43)$ & $5.67(0.40)$ & $5.75(0.43)$ & $5.88(0.43)$ \\
\hline BMI & $22.10(0.91)$ & $22.50(1.10)$ & $21.60(0.98)$ & $21.53(0.98)$ & $21.24(1.11)$ & $21.89(1.11)$ \\
\hline Exams score & $51.21(2.23)$ & $49.13(2.35)$ & $49.22(2.23)$ & $44.43(2.43)$ & $50.17(2.43)$ & $51.52(2.43)$ \\
\hline Coronary risk index & $2.35(0.34)$ & $3.10(0.28)$ & $2.66(0.27)$ & $3.17(0.30)$ & $2.72(0.32)$ & $3.01(0.34)$ \\
\hline
\end{tabular}

Table 1: Self-control schedule and clinical variables.

\begin{tabular}{|l|c|c|c|}
\hline Source & $\mathbf{R}^{\mathbf{2}}$ & Adjusted $\mathbf{R}^{2}$ & Sig. \\
\hline Age & 0.125 & 0.025 & 41711.403 \\
\hline Calories per day & 0.087 & -0.061 & 1509.385 \\
\hline Risk of malnutrition & 0.025 & -0.024 & 35.107 \\
\hline Baseline FBS & 0.052 & -0.067 & 5027.607 \\
\hline FBS before exams & 0.125 & 0.018 & 0.000 \\
\hline RBS & 0.047 & -0.143 & 0.000 \\
\hline BMI & 0.014 & -0.061 & 0.000 \\
\hline Exams score & 0.056 & 0.007 & 2602.667 \\
\hline Coronary risk index & 0.015 & -0.007 & 2706.336 \\
\hline Test between & 0.000 \\
\hline
\end{tabular}

Test between-subjects effects significantly showed that students differed on the SCS variable by grouped by gender. FBS: Fasting Blood Sugar levels; RBS: Random Blood Sugar Levels; BMI: Body Mass Index

Table 2: Tests between-subjects effects. 
survey on students using the daytime sleepiness scale seemed to be consistent with Van Cauter et al. [24]. However, one limitation in this study was the failure to fully retrieve sleep questionnaires from students as they hurriedly head towards examination hall and even afterwards.

Dieting is known to restrict one's caloric intake, and might produce lower glucose level, and this in turn, could possibly override the willpower needed to refrain from eating. This study could not capture students on diet restrictions.

Processes that rely heavily on the prefrontal cortex might require more glucose because the prefrontal cortex generally involves effortful, controlled, and executive processes. These processes are useful for decision making and logical reasoning and are prominent determinants of self-control.

\section{Conclusion}

Self-control task could possibly depend on glucose.

\section{Acknowledgement}

This work was sponsored by the authors. The authors duly acknowledge the staffs of Medical Biochemistry, Univ. of Ghana Medical School.

\section{References}

1. Gailliot MT, Baumeister RF (2007) The physiology of willpower: linking blood glucose to self-control. Pers Soc Psychol Rev 11: 303-327.

2. DeWall CN, Baumeister RF, Stillman TF, Gailliot MT (2007) Violence restrained: Effects of self-regulatory capacity and its depletion on aggressive behavior. Journal of Experimental Social Psychology 43: 62-76.

3. Finkel EJ, Campbell WK (2001) Self-control and accommodation in close relationships: an interdependence analysis. J Pers Soc Psychol 81: 263-277.

4. Vohs KD, Heatherton TF (2000) Self-regulatory failure: a resource-depletion approach. Psychol Sci 11: 249-254.

5. Gordijn EH, Hindriks I, Koomen W, Dijksterhuis A, Van Knippenberg A (2004) Consequences of stereotype suppression and internal suppression motivation: a self-regulation approach. Pers Soc Psychol Bull 30: 212-224.

6. Richeson JA, Baird AA, Gordon HL, Heatherton TF, Wyland CL, et al. (2003) An $\mathrm{fMRI}$ investigation of the impact of interracial contact on executive function. Nat Neurosci 6: 1323-1328.

7. Richeson JA, Trawalter S (2005) Why do interracial interactions impair executive function? A resource depletion account. J Pers Soc Psychol 88: 934-947.
8. Richeson JA, Trawalter S, Shelton JN (2005) African Americans' implicit racial attitudes and the depletion of executive function after interracial interactions. Social Cognition 23: 336-352.

9. Vohs KD, Baumeister RF, Ciarocco NJ (2005) Self-regulation and selfpresentation: Regulatory resource depletion impairs impression management and effortful self-presentation depletes regulatory resources. Journal of Personality and Social Psychology 88: 632-657.

10. Rosenbaum MA (1980) Schedule for assessing self-control behaviors: Preliminary findings. Behavior therapy 1: 109-121.

11. Rosenbaum M (1990) Foreword. In: Rosenbaum M (eds), Learned resourcefulness: On coping skills, self-control, and adaptive behaviour Springer, New York.

12. Muraven M, Baumeister RF (2000) Self-regulation and depletion of limited resources: does self-control resemble a muscle? Psychol Bull 126: 247-259.

13. Laughlin SB (2004) The implications of metabolic energy requirements for the representation of information in neurons. In: Gazzaniga MS (ed.), The cognitive neurosciences (3rdedn), MA: MIT Press, Cambridge.

14. Siesjo BK (1978) Brain energy metabolism. Chichester, England.

15. Fell D (1997) Understanding the control of metabolism. London: Portland press

16. Metzler DE (2001) Biochemistry, the chemical reactions of living cells. San Diego: Academic Press.

17. Newsholme EA, Leech AR (1983) Biochemistry for the Medical Sciences. New York: Wiley Weiss V (1986) From memory span to the quantum mechanics of intelligence. Personality and Individual Differences 7: 737-749.

18. Baumeister RF, Bratslavsky E, Muraven M, Tice DM (1998) Ego depletion: is the active self a limited resource? J Pers Soc Psychol 74: 1252-1265.

19. Baumeister RF, Heatherton TF, Tice DM (1994) Losing control: How and why people fail at self-regulation. San Diego, CA: Academic Press.

20. Ryan CM (1988) Neurobehavioral complications of type I diabetes. Examination of possible risk factors. Diabetes Care 11: 86-93.

21. Dahlquist G, Källén B, Swedish Childhood Diabetes Study Group (2007) School performance in children with type 1 diabetes--a population-based register study. Diabetologia 50: 957-964

22. McCarthy AM, Lindgren S, Mengeling MA, Tsalikian E, Engvall JC (2002) Effects of diabetes on learning in children. Pediatrics 109: E9.

23. Van Cauter E, Polonsky KS, Scheen AJ (1997) Roles of circadian rhythmicity and sleep in human glucose regulation. Endocr Rev 18: 716-738.

24. Banfield J, Wyland CL, Macrae CN, Munte TF, Heatherton TF (2005) The cognitive neuroscience of self-regulation. In: Baumeister RF, Vohs KD (eds) The handbook of self-regulation New York. Guilford 63-83. 